http://jmscr.igmpublication.org/home/ ISSN (e)-2347-176x ISSN (p) 2455-0450

crossref DOI: https://dx.doi.org/10.18535/jmscr/v7i9.52

Journal Of Medical Science And Clinical Research

\title{
An Observational Study to find out Frequency of Bronchial Asthma among Patients with Successful Treatment of Pulmonary Tuberculosis
}

\author{
Authors \\ Dr Surendra Kumar, Dr Sunil Kumar Agrawal \\ Assistant Professor, T.B. \& Chest Department, Patna Medical College \& Hospital, Patna, Bihar \\ *Correspondence Author \\ Dr Sunil Kumar Agrawal \\ Assistant Professor, Department of T.B. \& Chest, Patna Medical College and Hospital, Patna, Bihar, India
}

\begin{abstract}
Aim: To find out Frequency of Bronchial Asthma among post Tuberculosis patients with successful treatment of pulmonary tuberculosis (PTB).

Method: This is an observational study conducted at Chest department OPD at patna Medical College \& Hospital. After completion of TB treatment for PTB patients still presenting with cough, dyspnea and recurent wheezing were send to speciality clinic of chest department. According to diagnostic criteria which was spirometry patients were either excluded or included in the study after recording of complete history, thorough examination. Social sciences (SPSS) version 17 were used to analyze the data.

Result: 230 patients were examined, interviewed and PFTSs were done. Males were 108(47\%), females $122(53 \%)$ and Asthma was found in 70 (30\%) of patients with 40 (57\%) females and 30(43\%) males. Maximum numbers of patients were between 15 and 45 years of age.

Conclusion: In patients with history of successfully treated PTB previously Bronchial asthma is a common problem. To established the exact mechanism a large randomised control study should be conducted.
\end{abstract}

\section{Introduction}

There is a common belief that bronchial asthma and pulmonary tuberculosis do not occur together, yet in the researcher experiences the combination is sufficiently common. Most of the technologically advanced world has seen more than a century of declining incidence of tuberculosis (TB). Asthmatic responses can be altering and provoked by the respiratory infection which has been established from long time and involved or contribute in the development of asthma. The prevalence of asthma has rapidly increased over the last few decades to epidemic proportions and there are now an estimated 300 million sufferers worldwide, a total that is expected to rise dramatically over the next 15-20 years $^{[1]}$. Despite the advances in effective therapy, Asthma is associated with enormous healthcare expenditures and consequential economic burden associated with morbidity continues to escalate and disease control ${ }^{[2]}$.

The inflammation of chronic asthma appears to be far more complex than a simple eosinophilic inflammation. All cells of the airways- 
inflammatory and structural-are involved and become activated including $\mathrm{T}$ cells, eosinophils, mast cells, macrophages, epithelial cells, fibroblasts, and even bronchial smooth muscle cells $^{[3]}$. Asthma is characterised by remodelling of the airways ${ }^{[4]}$. A typical feature of airway remodelling is the increased thickness of the reticular layer of the basement membrane ${ }^{[5]}$.

Altering and provoking asthmatic response by the viral infection is awell-known factor ${ }^{[6]}$. The association of fungal infections and asthma is also well known. development of airflow obstruction previous pulmonary tuberculosis infection and treatment is a major risk factor and it has been established in various studies ${ }^{[7,8]}$.

After complete treatment of pulmonary tuberculosis it has been observed in our daily clinical practice that asthma like symptoms were present in many patients. This study was aimed to find out frequency of bronchial asthma among post tuberculosis patients with successful treatment of pulmonary tuberculosis (PTB).

\section{Methods}

This is an observational study conducted at Chest department OPD at patna Medical College \& Hospital. After completion of TB treatment for PTB patients still presenting with cough, dyspnea and recurent wheezing were send to speciality clinic of chest department. According to diagnostic criteria which was spirometry patients were either excluded or included in the study after recording of complete history, thorough examination. Spirometry was considered as one of the major tool to diagnosed bronchial asthma. Spirometry is designed to identify and quantify functional abnormalities of the respiratory system. Sampling technique with non-probability convenience were used for the sampling purpose. Below age 12 years' children who were having asthma symptoms and allergic symptoms before the diagnosis of pulmonary tuberculosis were excluded
All patient was signed a consent before enrolling into the study and institutional ethical committee approval was taken before initiating the trial.

The patients are typically asked to breathe normally and then to take the deepest possible breath and then exhale as quickly and as hard as possible. From that maneuver the forced expiratory volume in the first second (FEV1) of exhalation is measured and com- pared to the entire volume of air that can be expelled in a forced expiration (forced vital capacity [FVC]). Spirometry is indicated as part of the initial diagnostic evaluation for asthma in all patients5 years old to test for airflow obstruction, the severity, and the short-term reversibility ${ }^{[9]}$.

Social sciences (SPSS) version 17 were used to analyze the data. Variables like gender, age, presence of asthma were presented as frequencies and were expressed as percentages. Results were shown in the form of tables.

\section{Result}

230 patients were examined, interviewed and PFTSs were done. Males were 108(47\%), females 122(53\%) and Asthma was found in $70(30 \%)$ of patients with $40(57 \%)$ females and 30(43\%) males (Table 1). Maximum numbers of patients were between 15 and 45 years of age (Table 2).

Table 1: Age \& Gender Wise Distribution of study participants

\begin{tabular}{|l|c|c|}
\hline Age (Years) & Male (\%) & Female (\%) \\
\hline$\leq 15$ & $10(4.3 \%)$ & $12(5.2 \%)$ \\
\hline $16-30$ & $41(17.8 \%)$ & $47(20.4 \%)$ \\
\hline $31-45$ & $35(15.2 \%)$ & $40(17.4 \%)$ \\
\hline$>45$ & $22(9.6 \%)$ & $23(10 \%)$ \\
\hline Total & $108(47 \%)$ & $122(53 \%)$ \\
\hline
\end{tabular}

Among 70 patients who developed asthma $44 \%$ were in the age range 16-30 years and $40 \%$ in range 31-45 years. Only 7\% patients were below 15 years of age (Table 2 ). 
Table 2: Age \& Gender wise distribution of patients in whom Asthma developed

\begin{tabular}{|l|c|c|}
\hline Age (Years) & Male (\%) & Female (\%) \\
\hline$\leq 15$ & $2(2.9)$ & $3(4.3 \%)$ \\
\hline $16-30$ & $14(20 \%)$ & $18(25.7 \%)$ \\
\hline $31-45$ & $12(17.1 \%)$ & $15(21.4 \%)$ \\
\hline$>45$ & $2(2.9 \%)$ & $4(5.7 \%)$ \\
\hline Total & $30(43 \%)$ & $40(57 \%)$ \\
\hline
\end{tabular}

\section{Discussion}

The relationship between asthma and respiratory infections is an important one, in two respects. Firstly, respiratory infections with viruses and allied organisms, such as Mycoplasma and Chlamydia species, are frequent causes of exacerbations of asthma, particularly in children, and are thus important triggers. Secondly, respiratory syncytial virus (RSV) infection and, more recently, Chlamydia infection have been proposed as possible causes of asthma. Viral respiratory tract infections are frequent and usually self-limited illnesses. For patients at risk for asthma, or with existing asthma, viral respiratory tract infections can have a profound effect on the expression of disease or loss of control. New evidence has shown that wheezing episodes early in life with the common cold virus, human rhinovirus, is a major risk factor for the later diagnosis of asthma at age six years.

In this observational study our main focus on the frequency of bronchial asthma after taking anti tuberculosis drugs. Reversible obstruction was found in almost $24 \%$ patients among $57 \%$ female patients which was diagnosed but bronchial spirometry test. It was also being observed that involvement of younger patients was with great numbers.

It is evident from epidemiological studies that pulmonary impairment is relatively common among patients with a history of TB. Clinical trials investigating new drug regimens for TB should consider including lung function tests to evaluate the impact of these therapies on long- term pulmonary morbidity. Given the variety of lung function abnormalities, management of TB can potentially be pulmonary impairment specific and could target specific underlying immunopathology mechanisms. Furthermore, investigating the role of common variants in TBassociated lung injury may provide insight into the immunopathogenesis of PIAT.

Tuberculosis is characterized of chronic caseous granulomatous inflammation resulting in devastating tissue damage if left untreated ${ }^{[10]}$. As the most common site of involvement, pulmonary TB can cause permanent obstructive or restrictive pulmonary function impairment, which in turn can contribute to the pathogenesis of COPD ${ }^{[1,12,13]}$. In a nationwide survey in South Africa, the strongest predictor of COPD is a history of pulmonary TB, with odds ratio (OR) of 4.9 (95\% CI 2.6-9.20) for males and 6.6 (95\% CI 3.7-11.9) for females ${ }^{[14]}$. The study is, however, limited by the use of selfreported symptoms to define COPD.

In future, previous treatment and pulmonary tuberculosis infection is a risk factor for development of obstructive airway dis- eases like chronic obstructive pulmonary disease which already had confirmed by several study conducted past $^{[15,16]}$.

\section{Conclusion}

In patients with history of successfully treated PTB previously Bronchial asthma is a common problem. To established the exact mechanism a large randomised control study should be conducted.

\section{References}

1. Holgate S.T., Polosa R. Treatment strategies for allergy and asthma. Nat. Rev. Immunol. 2008;8:218-230.

2. Bahadori K., Doyle-Waters M.M., Marra C., Lynd L., Alasaly K., Swiston J., Fitz Gerald J.M. Economic burden of asthma: a systematic review. BMC Pulm. Med. 2009;9:24. 
3. Barnes P (1996) NO or no NO in asthma? Thorax 51:218-220.

4. Bousquet J, Chanez P, Lacoste JY, et al. (1992) Asthma: a disease remodeling the airways. Allergy 47:3-11

5. Redington AE, Springall DR, Ghatei MA, et al. (1997) Airway endothelin levels in asthma: influence of endobronchial allergen challenge and maintenance corticosteroid therapy. Eur Respir J 10:1026-1032.

6. Ozmen S, Tomac N, Uysal A, Arslan Z, Kuyucu N, Yoney A. Tuberculin responses in children with aller- gic diseases. Allergy 2002;57:1059-62.

7. Manezes AM, Hallal PC, Perez-padila R, Jardim JR, Muiño A, Lopez MV, et al. Tuberculosis and airway obstruction: evidence from PLATINO study in Latin America. Eur Respir J 2007;30:1180-5.

8. Jordan TS, Spencer EM, Davies P. Tuberculosis, bronchiectesis and chronic airflow obstruction. Res- pirology 2010;15:623-8.

9. Expert panel report 3: guidelines for the diagnosis and management of asthma. Bethesda MD: National Institutes of Health, National Asthma Education and Prevention Program; 2007. NIH Publication No. 08-4051. Available from http:// www.nhlbi.nih.gov/guidelines/ asthma/asthgdln.pdf. Accessed February 29, 2008.

10. Elkington P, Shiomi T, Breen R, Nuttall RK, Ugarte-Gil CA, et al. MMP-1 drives immuno- pathology in human tuberculosis and transgenic mice. J Clin Invest. 2011;121:1827-1833.

11. Hnizdo E, Singh T, Churchyard G. Chronic pulmonary function impairment caused by initial and recurrent pulmonary tuberculosis following treatment. Thorax. 2000;55:32-38.
12. Chung KP, Chen JY, Lee $\mathrm{CH}, \mathrm{Wu} \mathrm{HD}$, Wang JY, et al. Trends and predictors of changes in pulmonary function after treatment for pulmonary tuberculosis. Clinics (Sao Paulo) 2011;66:549-556.

13. Pasipanodya JG, Miller TL, Vecino M, Munguia G, Garmon R, et al. Pulmonary impairment after tuberculosis. Chest. 2007;131:1817-1824.

14. Ehrlich RI, White N, Norman R, Laubscher R, Steyn K, et al. Predictors of chronic bronchitis in South African adults. Int J Tuberc Lung Dis. 2004;8:369376.

15. Manezes AM, Hallal PC, Perez-padila R, Jardim JR, Muiño A, Lopez MV, et al. Tuberculosis and airway obstruction: evidence from PLATINO study in Latin America. Eur Respir J 2007;30:1180-5.

16. Jordan TS, Spencer EM, Davies P. Tuberculosis, bronchiectesis and chronic airflow obstruction. Res- pirology 2010;15:623-8. 